\title{
Iridocorneal Angle Foreign Body: A Case Report
}

S.Boutgayout", H.Atidi, N.Inzale, D.Jaafari, A.Arfaja, S.Belghmaidi I.Hajji A. Moutaouakil

Service d'ophtalmologie CHU Mohamed VI de Marrakech, Morocco

DOI: $10.36347 /$ sasjm.2021.v07i05.009

| Received: 19.03.2021 | Accepted: 23.04.2021 | Published: 28.05.2021

*Corresponding author: S. Boutgayout

Clinical Image

Copyright (C) 2021 The Author(s): This is an open-access article distributed under the terms of the Creative Commons Attribution 4.0 International License (CC BY-NC 4.0) which permits unrestricted use, distribution, and reproduction in any medium for non-commercial use provided the original author and source are credited.

\section{Item:}

We report the case of child $\mathrm{O}$ had 6 years old without any pathologic history, who presented a trauma of the left eye by à stick of wood.

The ophthalmologic examination objectified: an inferior punctiform corneal wound and a foreign body encrusted at the iridocorneal angle ( pic 1), surgical exploration showed a punctiform corneal wound, the conjunctival uncovering showed a perilimbic scleral wound of $1 \mathrm{~mm}$, the extraction of the foreign body was performed through a PAC, the entry and exit points of the foreign body were sutured, intracameral injection of cefuroxime and closure of the $\mathrm{PAC}$, the lens and the fundus eye were normal, without other foreign bodies, the evolution was satisfying.

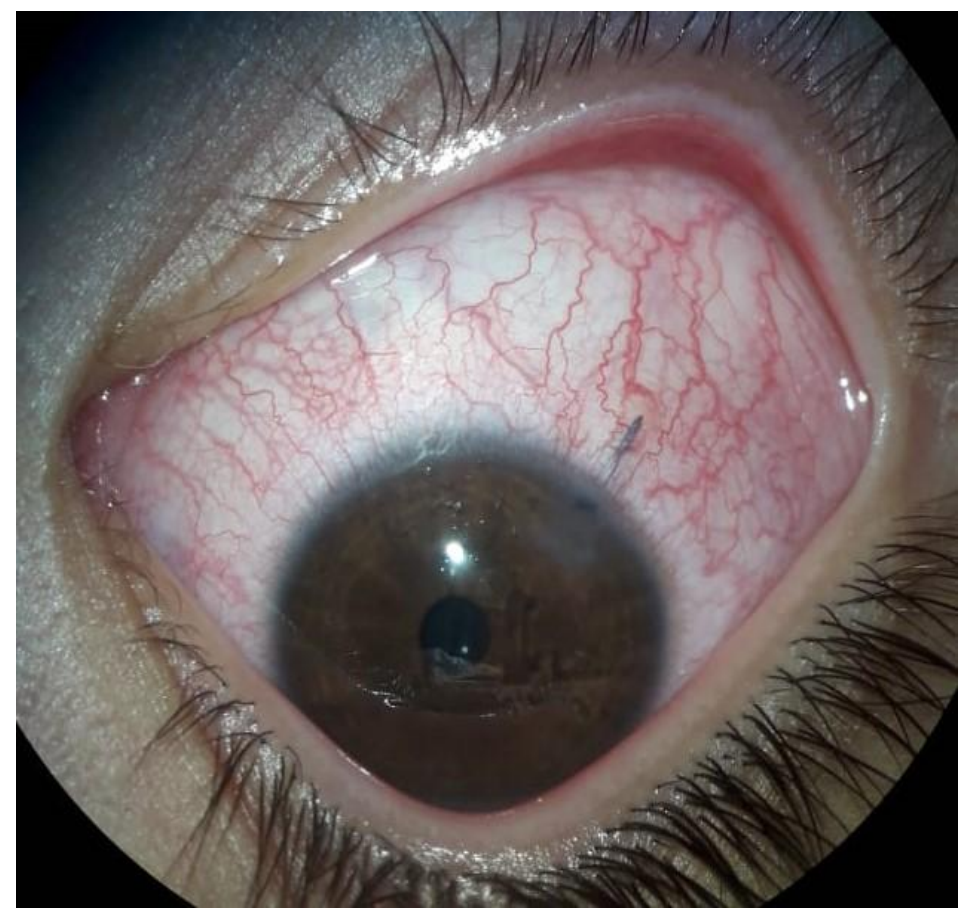

Pic-1 